\title{
High Dose Film Dosimeter Based on a Mixture of m-cresol Purple and Tetrabromo phenolphthalein Ethyl Ester Dyed Poly (vinyl alcohol)
}

\section{E. Faheem, Sh. Abdel-Moniem and M. A. El Ahdal}

Radiation Protection and Dosimetry Dept., National Centre for Radiation Research and Technology (NCRRT), Atomic Energy Authority (AEA) P.O., Box; 29 Nasr City, Egypt.

\footnotetext{
Gathering two $\mathrm{pH}$ indicator dyes m-cresol purple (MCP), Jetrabromophenolphthalein ethyl ester (TBPE), previously studied as individual dosimeter each at low dose application in the same polymer matrix (PVA) extends the application dose response to $60 \mathrm{kGy}$. This flexible plastic film changes its colour from green to red passing through yellow colour on exposure to $\gamma$-rays photons due to the consequent lowering of $\mathrm{pH}$ caused by $\mathrm{HCl}$ generated from the radiolysis of chloral hydrate. Effect of different concentrations of chloral hydrate on response of the film was investigated. The film shows excellent stability before and after irradiation. The film has excellent stability in $10 \%$ to $50 \%$ relative humidity range $(\mathrm{RH})$. The overall combined uncertainty (at $2 \sigma)$ associated with measurement of response $\left(\mathrm{A}_{\mathrm{i}} /\right.$ $\mathrm{A}_{0}$ ) at $438 \mathrm{~nm}$ for dose range $5-60 \mathrm{kGy}$ is $6.33 \%$. So this film has the ability to monitor the absorbed dose in low and moderate irradiation dose due to its excellent stability before and after irradiation with a significance confidence level.

Keywords: Tetrabromophenolphthalein ethyl ester, m-cresol purple, radiation dosimetry.
}

Radiation indicators used for identification of irradiated and un-irradiated products in radiation sterilization and food irradiation based on induced colour change by radiation. Due to chemical and physical changes caused in the exposed materials by ionizing radiations (Basfar, 2012) and their sensitivity towards various influence factors (dose rate, light, humidity, temperature etc.), (Shaheen et al., 2013), they are not used for quantitative dose measurements while label dosimeters may be used for quantitative dose measurements during radiation processing. These indicators may be labels, papers, inks, which 
undergo a visual colour change when exposed to ionizing radiation. These indicators based mainly on radio chromic dye (Kovacs et al., 2000). Other based on the $\mathrm{pH}$ indicator dye (Abdel- Fattah et al., 1996).

A new radiation sensitive indicator consisting of poly (vinyl alcohol) film containing pH-indicating dye and water soluble chlorine substance (Abdel Fattah et al., 1995) was studied. Several polymeric materials in the form of thin films have been successfully developed and used as dosimeters for routine use in gamma rays as well as electron beam radiation processing. Representative examples are radio chromic plastic films of various types (Abdel Fattah and Miller, 1996), Cellulose triacetate (Abdel Rehim et al., 1996), Gofchromic dosimetry media (Chu et al., 1990) and thin dyed polymeric films (Mclaughlin 1992). Based on the idea of mixing two dyes having different sensitivities to radiation in polymeric substrate were investigated (Abdel Rehim et al., 1995).

Radiation bleachable organic dyes were widely investigated (Ebraheem et al., 2005). For dose monitoring in radiation processing, the polymeric dyed flexible films are considered to be most commonly used as dosimeters and indicators (Abdel Rehim and Abdel Fattah, 1993) for monitoring the absorbed dose delivered by electron beams and gamma rays (Kovaces et al. 2002).

Ueno (1988) developed a radiation dosimeter from acid indicators by coating a high Molecular weight (MW) polymer support (e.g. polyester film) with a composition containing a halogen containing polymer (e.g. PVC), a pigment which changes colour with the changes of $\mathrm{pH}$. A chlorine-containing polymer is not necessary for this radiation to occur.

In the current work, thin films of PVA dyed with TBPE-MCP was investigated to be used as dosimeters for radiation processing.

\section{Experimental}

\section{Preparation of stock solution of TBPE-MCP}

\section{Preparation of stock solution of TBPE}

The stock solution of the indicator was prepared by dissolving $0.05 \mathrm{~g}$ of TBPE $\left(\mathrm{C}_{22} \mathrm{H}_{14} \mathrm{Br}_{4} \mathrm{O}_{4} \mathrm{M} . \mathrm{W}=661.96 \mathrm{~g} \backslash \mathrm{mol}\right.$ ) (Sigma-Aldrich, Inc., USA) in $50 \mathrm{ml}$ ethanol.

Egypt. J. Rad. Sci. Applic., Vol. 28, No. 1-2 (2015) 


\section{Preparation of stock solution of m-cresol purple}

The stock of sodium salt of the indicator was prepared by dissolving $0.04 \mathrm{~g}$ of m-cresol purple indicator (product of E. Merk) in $1.1 \mathrm{ml}$ aqueous $\mathrm{NaOH}$ $\{[\mathrm{NaOH}=0.1 \mathrm{~mol} \backslash 1]\}$ and then the volume was completed by ethanol in a $25 \mathrm{ml}$ volumetric flask.

\section{Preparation of TBPE-MCP Films}

Films were prepared by dissolving $5 \mathrm{~g}$ of PVA powder (average MW= 25000) fully hydrolysed $99-100 \%$ (product of G.T baker chemical Co. USA) in $100 \mathrm{ml}$ double distilled water at about $60^{\circ} \mathrm{C}$, the solution was kept well stirred for about $48 \mathrm{~h}$, then left to cool. To each $24 \mathrm{ml}$ of PVA $1 \mathrm{ml}, 2 \mathrm{ml} \& 3 \mathrm{ml}$ of TBPE were added and fixed concentration of MCP $(3 \mathrm{ml})$. Also $0.1 \mathrm{~g}, 0.2 \mathrm{~g}$ and $0.3 \mathrm{~g}$ chloral hydrate was added on fixed combined concentration of $3 \mathrm{ml}$ from both of TBPE and MCP and 24ml of PVA to study the effect of both dye concentration and chloral hydrate concentration on behaviour of dosimeter response. After preparing the six films, they were kept well stirred at room temperature for about $3 \mathrm{hr}$ 's in order to obtain a uniformity mixed solution. Each solution was poured on a $15 \times 15 \mathrm{~cm}^{3}$ horizontal glass plate, dried at room temperature for about $48 \mathrm{~h}$. After drying, the films were stripped from the glass plate, then cut into $1 \times 1 \mathrm{~cm}^{2}$ pieces and stored for further investigation. The thickness of the obtained films was found to be $0.049 \pm 0.005 \mathrm{~mm}(1 \delta)$.

\section{Apparatus}

The absorption spectra of the un-irradiated and irradiated films were measured throughout the wavelength range (200-800nm) using a UVKON 860 spectrophotometer. The film thickness was measured using a Digitrix-Mark thickness Gauge (precision $\neq 1$ um; $1 \delta$ ).

Irradiation was carried out with gamma rays using Gamma cell-220 Excel ${ }^{60} \mathrm{Co}$ irradiation facilities (Manufactured by MDS Nordian, Canada). The absorbed dose rate in water was measured by Frike dosimetery to be $\left\{\mathrm{G}\left(\mathrm{Fe}^{+3}=\right.\right.$ $2.35161 \mathrm{kGy} / \mathrm{h})\}$. The temperature during gamma ray irradiation was $30^{\circ} \mathrm{C}$, and the electronic equilibrium conditions were maintained during irradiation through keeping the films between two polystyrene slabs of $3 \mathrm{~mm}$ thickness.

Egypt. J. Rad. Sci. Applic., Vol. 28, No. 1-2 (2015) 


\section{Results and Discussion}

\section{Absorption Spectra}

The absorption spectra for the film TBPE-MCP from previous study (El- Kelany, 2011) shows a main absorption band in visible region characteristic of a blue peaking for TBPE/ PVA at $606 \mathrm{~nm}$. Amplitude of this band decreases gradually with the increase of absorbed dose of gamma ray photons. The film change its colour from blue to green and finally to pale green in presence of HCL source, and the useful dose range was found to be in the range 1-5 kGy. Also the absorption spectra of MCP/ PVA films from previous study (Eid, 2008) shows a main absorption band in the visible region characteristic to the yellow peaking at $417 \mathrm{~nm}$. The amplitude of the absorption band decreases and shifts to lower wavelength with the increase of absorbed dose and a new absorption band, peaking at $521 \mathrm{~nm}$ characteristic of a red colour is formed and its amplitude increases gradually with the increase of absorbed dose. The radiation induced colour change of these films from yellow (the alkaline form of $\mathrm{MCP}$ ) to red (the acidic form of MCP) indicating acid formation. The useful dose range was found to be in the range of $2-6 \mathrm{kGy}$.

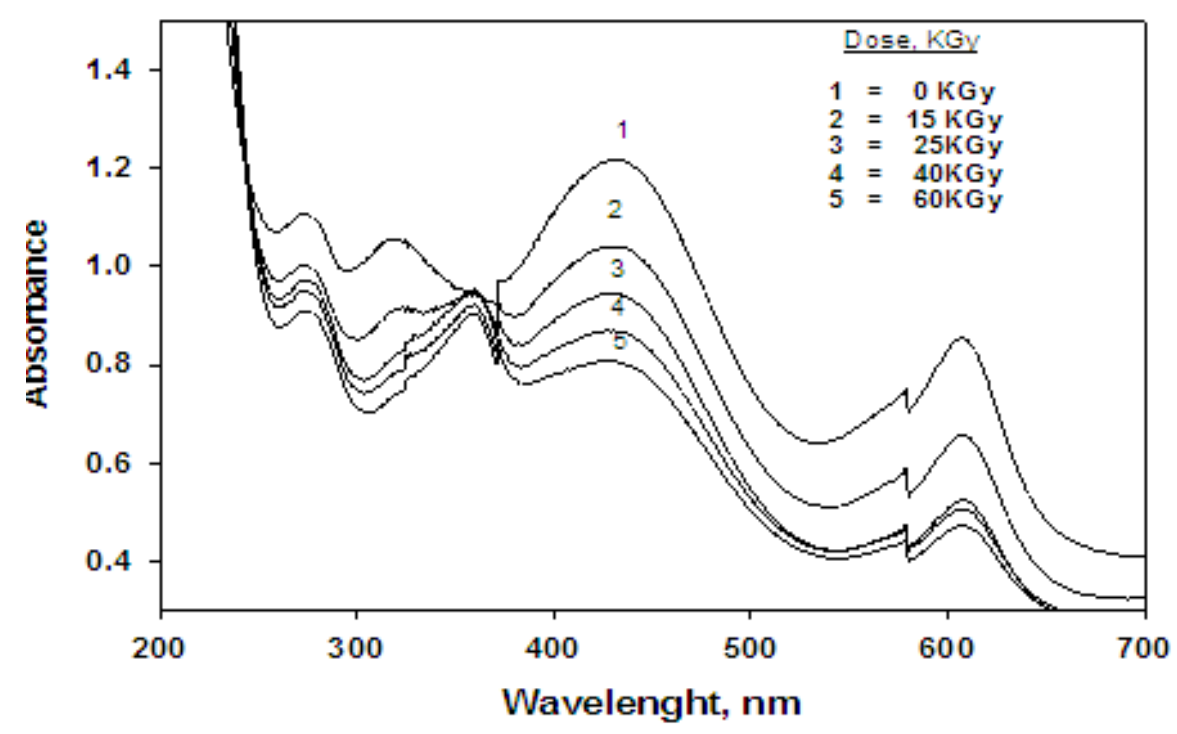

Fig. 1.a The absorption spectra of TBPE, MCP/ PVA films un-irradiated and irradiated to different doses without chloral hydrate.

Egypt. J. Rad. Sci. Applic., Vol. 28, No. 1-2 (2015) 
In the current work, gathering the two above mentioned dyes in the same polymer matrix as TBPE, MCP/PVA extend the dose range up to $60 \mathrm{kGy}$ for serving high dose application. Fig. 1a.\& 1b. shows the absorption spectra of the un-irradiated and irradiated films measured throughout the wavelength range (300-700nm). The absorption spectra of the TBPE, MCP $\backslash$ PVA (0.2 phr TBPE, $0.32 \mathrm{phr} \mathrm{MCP}$ ) without chloral hydrate recorded before and after irradiation to different doses.

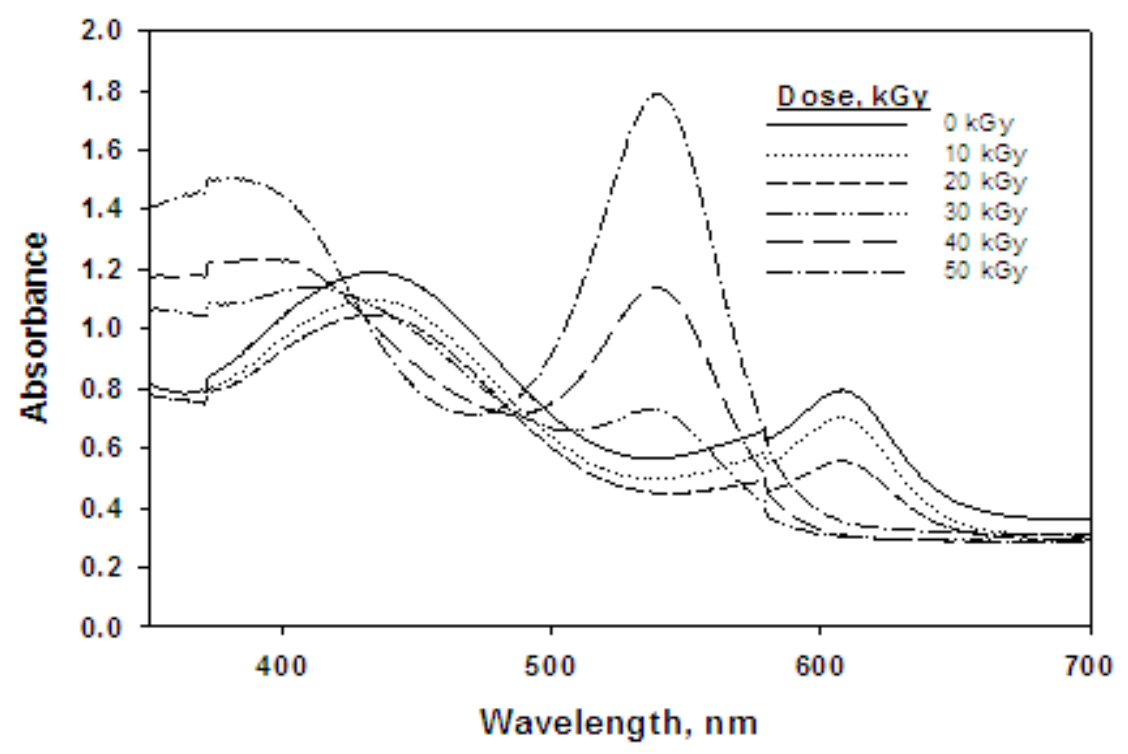

Fig. 1b. The absorption spectra of TBPE, MCP/ PVA films un-irradiated and irradiated to different doses with chloral hydrate.

The absorption spectrum of un-irradiated film shows a main absorption band in the visible region characteristic of a blue colour peaking at $606 \mathrm{~nm}$, and another absorption band at $438 \mathrm{~nm}$ characteristic of a yellow colour peaking. The green colour is observed due to the visual sensation of mixed ratios of dyes. On irradiation we noticed more significance sensitivity for MCP in comparison with TBPE towards the absorbed dose but no peak observed in the red range due to absence of $\mathrm{HCl}$ source (still alkaline phase). In the presence of chloral hydrate (16.6 phr), We noticed decrease in the intensity of MCP and TBPE with increase of absorbed dose. A new absorption band, peaking at $538 \mathrm{~nm}$ characteristic of a red colour is formed, its amplitude increases with the increase of absorbed dose. 
The radiation-induced colour change of these films from green colour to red colour through intermediate yellow colour indicates acid formation. The dose at which the red colour appears depends on the concentration of both dyes and chloral hydrate in the film. Fig. 2. shows the response curve of TBPE, MCP PVA containing $0.2 \mathrm{phr}$ TBPE, $0.32 \mathrm{phr}$ MCP and $16.6 \mathrm{phr}$ chloral hydrate. It can be noted that the curve have S-shape characteristic of $\mathrm{pH}$ indicator phenomena in acid-base titration. The figure shows the response curve in terms of optical density after irradiation $\left(\mathrm{A}_{\mathrm{i}}\right)$ to optical density before irradiation $\left(\mathrm{A}_{0}\right)$ at $438 \mathrm{~nm}$. The curve shows the useful dose range extends up to $60 \mathrm{kGy}$. So the presence of both dyes together transfer the response from limited application in low doses to more wide application covering the low and intermediate dose range. These phenomena may be due to dissociation takes place for the absorbed dose between both two dyes having different sensitivity which leads to extend the dose range.

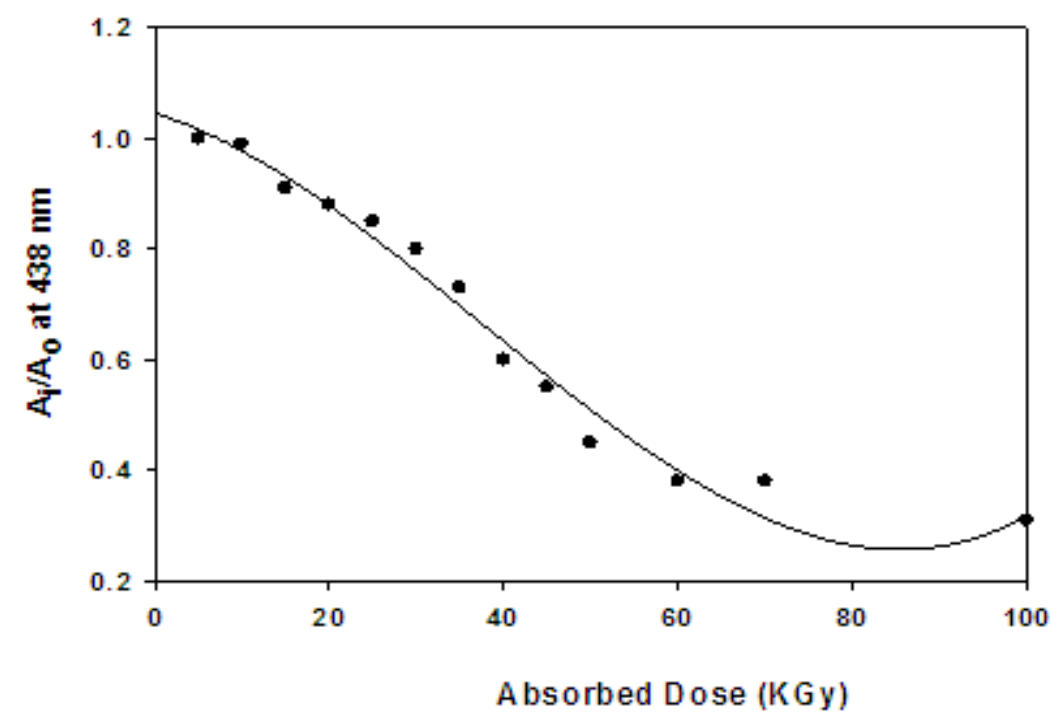

Fig. 2. Change of $A_{i} \backslash A_{0}$ at $438 \mathrm{~nm}$ as a function of absorbed dose of $0.2 \mathrm{phr}$ TBPE, 0.32 phr MCP\PVA films. (16.6phr chloral hydrate).

Fig. 3. shows the response curve of TBPE, MCP $\backslash$ PVA film containing different concentration of dyes $0.06 \mathrm{phr}, 0.13 \mathrm{phr}, 0.2 \mathrm{phr}$ TBPE and $0.32 \mathrm{phr}$ $\mathrm{MCP}$ and fixed concentration of chloral hydrate (16.6phr). It can be seen that all curves have the same trend and reaches saturation at doses proportional to the concentration of TBPE dye.

Egypt. J. Rad. Sci. Applic., Vol. 28, No. 1-2 (2015) 


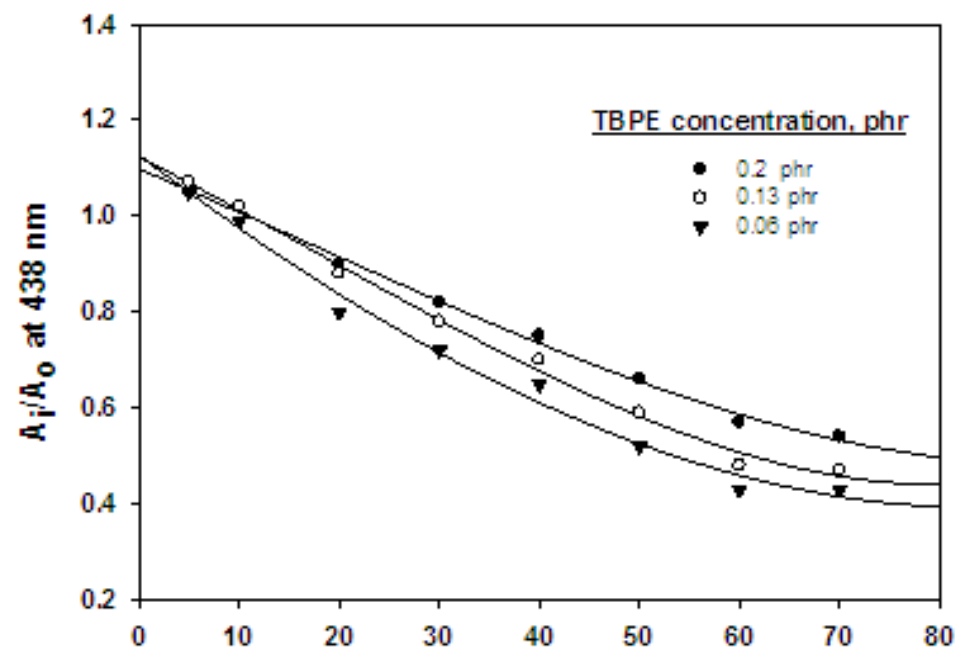

Absorbed Dose, kGy

Fig. 3. Change of Ai/ Ao as a function of absorbed dose of TBPE, MCP/ PVA films with different concentrations of TBPE dye.

Fig. 4. shows the response curve of TBPE, MCP $\backslash$ PVA film containing different concentrations of chloral hydrate and fixed concentrations of dyes (16.6phr, 33.2phr, 49.8phr). All curves shown in figure have the same trend but differ in the slope value (slope of initial part of curves). The slope increases with increase chloral hydrate values.

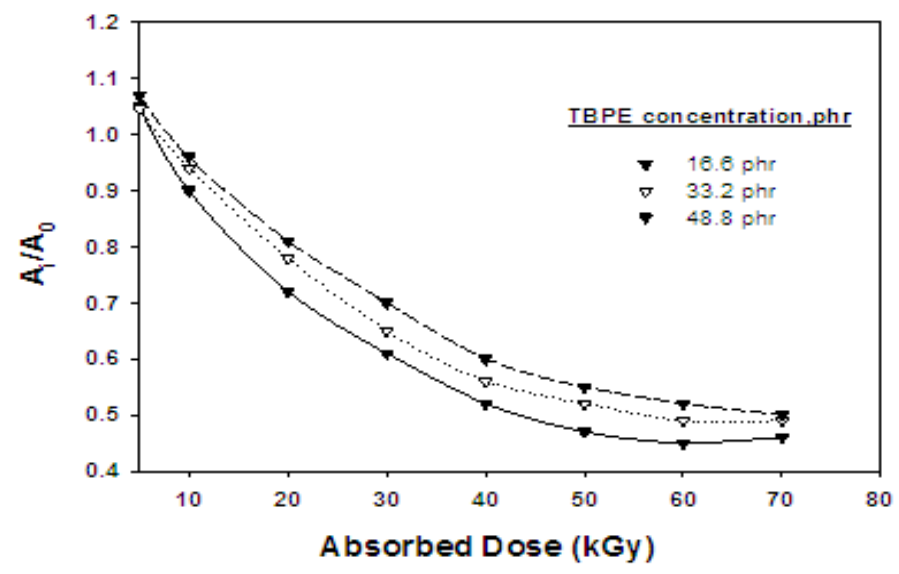

Fig. 4. Change of Ai/ Ao as a function of absorbed dose of TBPE, MCP/ PVA films with different concentrations of chloral hydrate.

Egypt. J. Rad. Sci. Applic., Vol. 28, No. 1-2 (2015) 


\section{Humidity during irradiation}

The effect of $\mathrm{RH}$ during irradiation on the response was investigated by irradiate TBPE, MCP $\backslash$ PVA films (16.6phr CH), (0.2phr TBPE, 0.32phr MCP) at $438 \mathrm{~nm}$ by $35 \mathrm{kGy}$ at different relative humidity $(0 \%, 11 \%, 33 \%, 54 \%, 76 \%, 92 \%)$. Irradiation was carried out while the films were suspended over various saturated salt solutions in an enclosed jar except for the $0 \% \mathrm{RH}$ which was embedded over dried silica gel. Fig. 5. shows the variation in optical density after irradiation $\left(\mathrm{A}_{\mathrm{i}}\right)$ to optical density before irradiation $\left(\mathrm{A}_{\mathrm{o}}\right)$ as a function of percentage $\mathrm{RH}$ during irradiation relative to that at $33 \%$. It was found that, the films have no appreciable effect in the range of RH (10-50\%), although the response shows somewhat different sensitivities at both higher and lower humidity.

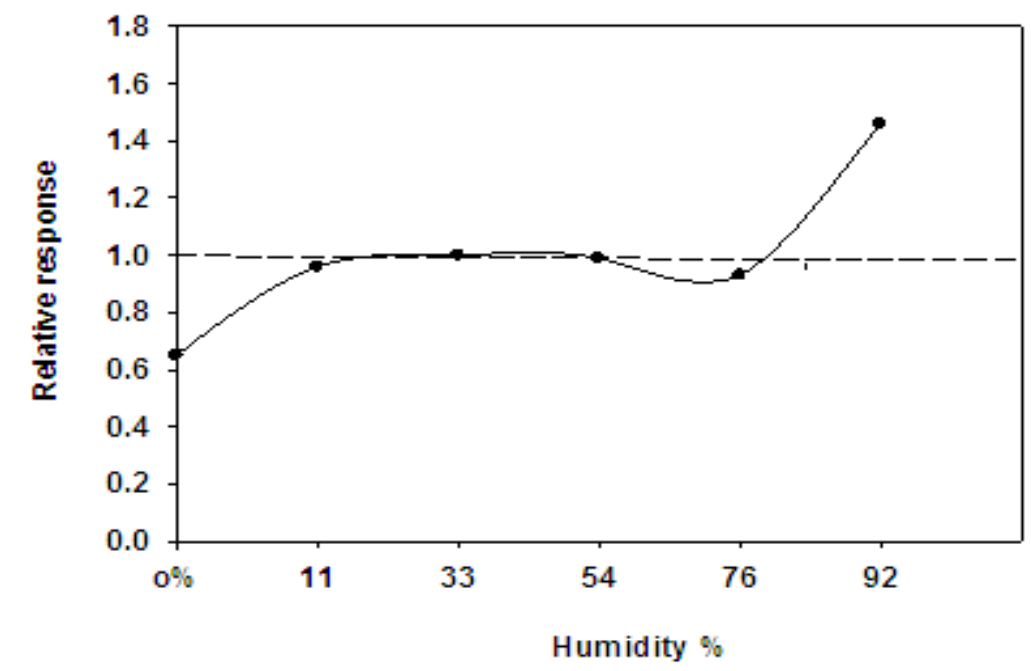

Fig. 5. Variation of relative response of TBPE, MCR/ PVA films as a function of relative humidity during irradiation at $438 \mathrm{~nm}$.

\section{Assessment of uncertainties}

To be meaningful, a measurement of gamma ray shall be accompanied by an estimate of the uncertainty in the measured value. Factors contributing to the total uncertainty may be separated into two types, type A and type B (ISOI ASTM, 2002 and Taylor et al., 1994). The first factor is associated mainly with the measuring equipment and the film while the second is mainly related to the calibration. The reproducibility of the UVKON spectrophotometer was determined by reading the absorbance value (at $438 \mathrm{~nm}$ wavelength and absorbance level 0.8 ) of irradiated films several times (one hundred readings per

Egypt. J. Rad. Sci. Applic., Vol. 28, No. 1-2 (2015) 
film). From the data obtained, it was found that the coefficient of variation $(1 \sigma)$ is $\pm 0.2 \%$, reflecting the precession of the spectrophotometer. The reproducibility of the measurements of several films (10 times for film) was found to be $1.8 \%(1 \sigma)$. On the other hand, the type "A" uncertainties (at one standard deviation, $1 \sigma$ ) arising during calibration over the useful response range were found to be $\pm 2.6 \%$. The combined uncertainties $\left(U_{c}\right)$ can be obtained by combining all the components in quadrature at one standard deviation $(1 \sigma)$ as follow:

$$
\mathrm{Uc}=\sqrt{ }(0.2)^{2}+(2.6)^{2}+(1.8)^{2}=3.168
$$

The combined uncertainty (at two standard deviations, i.e $2 \sigma$, approximately equal to $95 \%$ confidence level) is found by multiplication of Uc at $(1 \sigma)$ by two. Hence the combined uncertainty is $6.33 \%$.

\section{Pre-irradiation stability}

The colour stability of TBPE, MCP $\backslash$ PVA films containing (16.6phr chloral hydrate, $0.2 \mathrm{phr}$ TBPE, $0.32 \mathrm{phr} \mathrm{MCP}$ ) at $438 \mathrm{~nm}$ before irradiation were tested by storing the films at $35 \% \mathrm{RH}$ at room temperature $\left(25 \pm 3^{\circ} \mathrm{C}\right)$ in the dark and under laboratory fluorescent light.

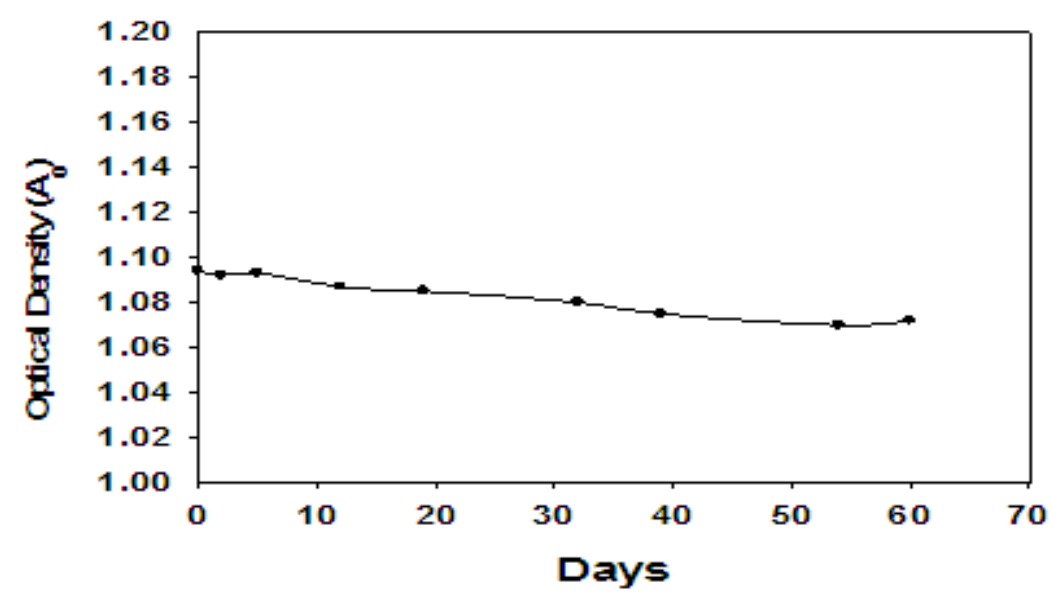

Fig. 6. Post-irradiation stability of TBPE, MCP/ PVA films stored in diurnal cycles of day light at room temperature in $25^{\circ} \mathrm{C}$ at $438 \mathrm{~nm}$.

The absorbance of the films was measured at $438 \mathrm{~nm}$ wavelength at different time intervals during the pre-irradiation storage period of 60 days. The change in absorbance at $438 \mathrm{~nm}$ as a function of storage time is shown in Fig. 6. It can be seen that the films have excellent stability, just $2 \%$ decrease through 60 days.

Egypt. J. Rad. Sci. Applic., Vol. 28, No. 1-2 (2015) 


\section{Post irradiation stability}

The colour stability of TBPE, MCP/ PVA films containing (16.6phr chloral hydrate, TBPE $0.2 \mathrm{phr}$ and MCP $0.32 \mathrm{phr}$ ) at $438 \mathrm{~nm}$ before irradiation were tested by storing the films at $35 \% \mathrm{RH}$ at room temperature $\left(25 \pm 3^{0} \mathrm{C}\right)$ in the dark and under laboratory fluorescent light. The change in absorbance at $438 \mathrm{~nm}$ as a function of storage time is shown in Fig. 7. It can be seen that the films have excellent stability, just $2 \%$ decrease through 60 days storage time in dark and $4 \%$ decrease in light.

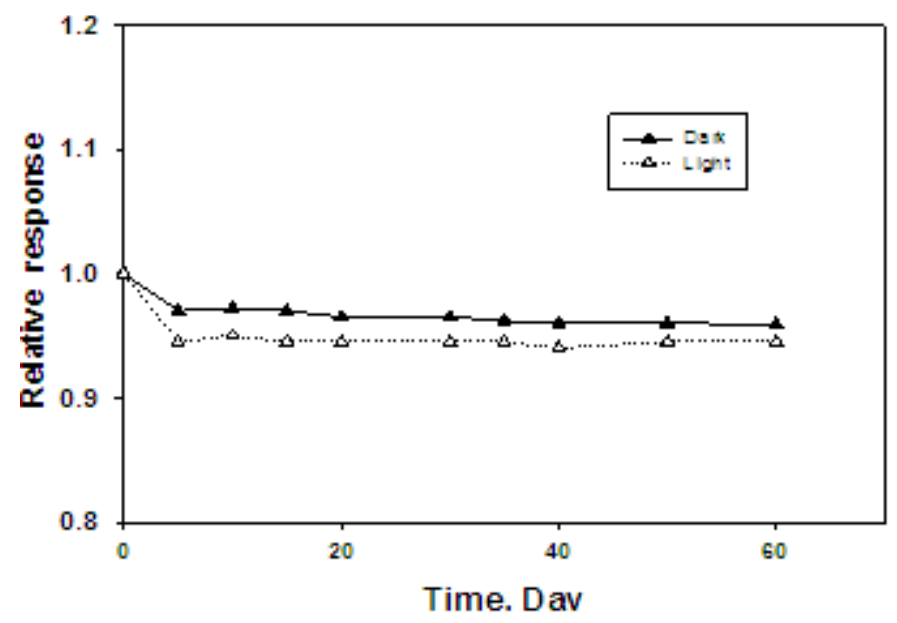

Fig. 7. Post-irradiation stability of TBPE, MCP/ PVA films stored in diurnal cycles of day light at room temperature in $25^{\circ} \mathrm{C}$ at $438 \mathrm{~nm}$.

\section{Conclusion}

Films made of PVA dyed with mixed dyes TBPE-MCP are useful radiation dosimeters in the dose range 5-60kGy. The films are highly stable for long times in dark and are not affected by relative humidity changes in the range of (10-60\%). These films are easy to make and thus, amenable for large-scale production and application for routine irradiation process of food and medical devices. The combined uncertainty at $2 \sigma$ using TBPE/ MCP/ PVA films was found to be $6.33 \%$.

\section{References}

Abdel-Fattah, A. A. and Miller A. (1996) Temperature, humidity and time combined effects on radiochromic film dosimeters. Radiat .Phys. Chem., 47, 611.

Abdel-Fattah, A. A., El-Kelany, M. and Abdel-Rehim, F. (1995) Development of a radiation-sensitive indicator. Radiat. Phys. Chem., 51, 317.

Egypt. J. Rad. Sci. Applic., Vol. 28, No. 1-2 (2015) 
Abdel-Fattah, A., Ebraheem S., El-Kelany, M. and Abdel-Rehim, F. (1996) Highdose film dosimeters based on bromophenol blue or xylenol orange dyed polyvinyl alcohol. Appl. Radiat. Isotop, 47, 345.

Abdel-Rehim F. and Abdel-Fattah, A. (1993) A thin-film radiation monitoring label and dosimetry system. Appl. Radiat. Isotop., 44, 1047.

Abdel-Rehim F. and Abdel-Fattah, A., Ebraheem, S. and Ali Z. (1996) Improved of the CTA dosimetric properties by the selection of read-out wavelength and the calculation of the spectrophotometric quantity. Appl. Radiat. Isotop., 47, 247.

Abdel-Rehim F. and Ebraheem, S., (1995) Development of a thin-film radiation monitoring label and dosimetery system. Radiat. Prot. Dos., 44, 1047.

Basfar, A., Rabeah, A. and Al Zahrany, A. (2012) Radiation-induced color bleaching of methyl red in polyvinyl butyral film dosimeter. Radiat. Phys. Chem., 80, 1263.

Chu, R. D., Van Dyk G., Lewis D. F., Ohera, K. P., Bucland, B. W. and Dinelle, F. (1990) Gafachromic Dosimetry Media: A new high dose, thin film routine dosimeter and dose mapping tool. Radiat. Phys. Chem., 35,767.

Ebraheem, S., Beshir, W. B. and Eid, S. (2005) investigation of dyed film based on 2, 6dichlorophenol-indophenol dyed poly (vinyl alcohol) and poly (vinyl butyral) for possible use in high-dose processing dosimetry. Arab. J. nucl. Science Applic., 38, 1.

El-Kelany, M. (2011) Effect of $\gamma$-Radiation on the Physical Properties of poly (vinyl alcohol) dyed with Tetrabromophenolphtalein Ethyl Ester. Eqypt. J. Rad. Sci. Applic., 24, 153.

Kovács, A., Baranyai, M., Wojnárovits, L., McLaughlin, W. L., Miller, S. D., Miller, A., Fuochi, P., Lavalle, M. and Slezsák, I. (2000) Application of the sunna dosimeter film in gamma and electron beam radiation processing. Radiat. Phys. Chem., 57, 691.

Kovacs, A., Ebraheem, S. and Eid, S. (2002) a new dyed poly (vinyl alcohol) film for high-dose applications, Radiat. Phys. Chem., 63, 807.

Mclaughlin, W. L. (1992) A thin dyed plastic dosimeter for large radiation doses. Appl. Radiat. Isotop., 43, 1503.

Shaheen, A., Taqmeem, H., Amir, S. and Qamar, I. (2013) The feasibility of reactive dye in PVA films as high dosimeter. Basic \& Appli. Sci., 9, 420.

Ueno K. (1988) Development of a plastic dosimeter for industrial use with high doses. Radiat. Phys. Chem., 31, 467.

(Received: 23/02/2015;

accepted: $21 / 04 / 2015)$

Egypt. J. Rad. Sci. Applic., Vol. 28, No. 1-2 (2015) 


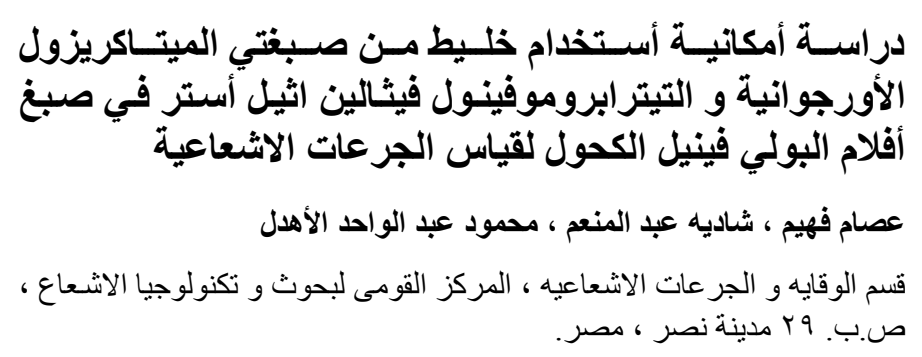

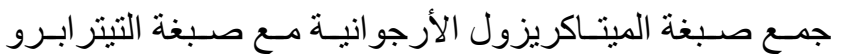

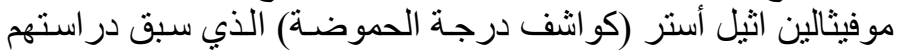

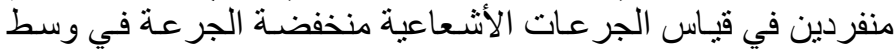

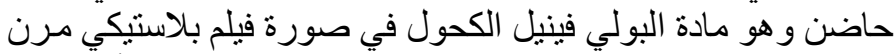

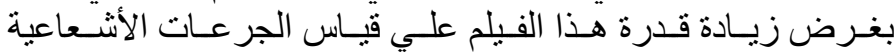

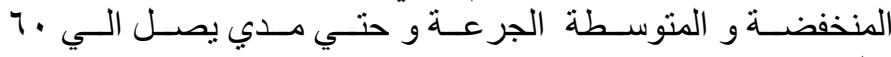

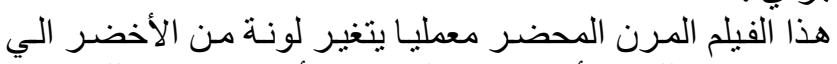

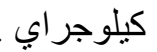

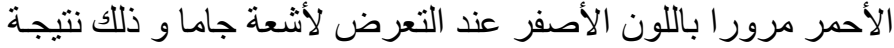

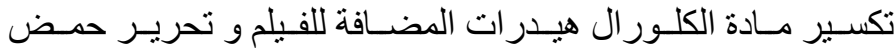

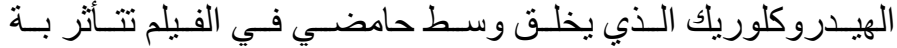

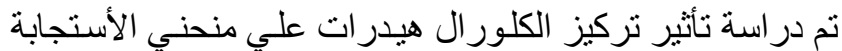

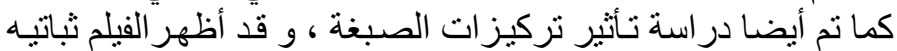

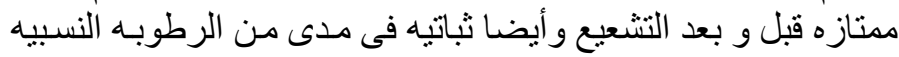

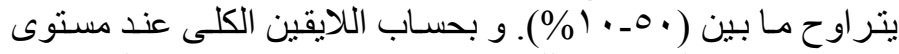

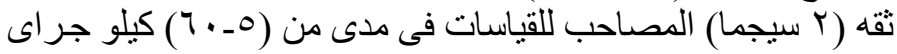

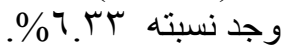

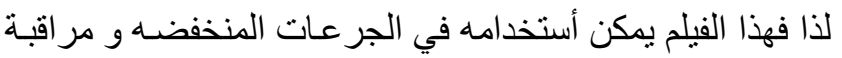

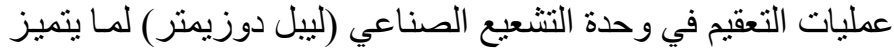
بة من ثباتيه ممتازه قبل و بعد التشعيع و مستوي نقة مناسب.

Egypt. J. Rad. Sci. Applic., Vol. 28, No. 1-2 (2015) 